\title{
Targeting Effectiveness of Social Transfer Programs in Botswana: Means-tested versus Categorical and Self-selected Instruments
}

Tebogo B. Seleka and Khaufelo R. Lekobane

We will evaluate the targeting effectiveness of fifteen social transfer programs in Botswana using data from the Botswana Multi-topic Household Survey 2015/16. Results reveal that, with one exception, these programs provide minimal coverage of the poor. Further, these programs are largely ineffective in targeting the poor and inclusion errors allow large leakages to the nonpoor. Benefit incidence analysis reveals that most social assistance and asset transfer programs and a public works program are progressive and pro-poor. Programs for building human capital through financing tertiary education are progressive but not pro-poor, suggesting inequality in access to higher education. Because education is a pathway out of poverty, this may contribute to intergenerational transmission of poverty. Means-tested programs do not necessarily target the poor better than categorical and self-targeted programs. Thus, eligibility criteria may not be strictly enforced during the selection of beneficiaries for major means-tested programs. Reforms are needed to improve targeting effectiveness and minimize program leakages.

Keywords: benefit incidence, poverty, social transfers, targeting effectiveness

Botswana has been one of the world's fastest growing economies since gaining independence in 1966 (United Nations Development Programme, 2009; World Bank, 2019). This impressive record is mainly attributed to diamond exports, prudent macroeconomic management, and good governance (Maipose, 2008). Nevertheless, the country has faced socioeconomic challenges of unemployment, poverty, and income inequality (Lekobane \& Seleka, 2017; Ulriksen, 2012; World Bank, 2015). These challenges owe to the dependence of the economy on the capital-intensive activity of mining and the poor performance of labor-intensive

Tebogo B. Seleka, PhD, is executive director, Botswana Institute for Development Policy Analysis, Gaborone, Botswana. Also at Botswana Institute for Development Policy Analysis, Khaufelo R. Lekobane, MA, is research fellow. 
activities - for example, agriculture and manufacturing - as well as the slow pace of overall economic diversification. Thus, economic growth in Botswana has not been a sufficient condition for sustained poverty reduction (Ministry of Finance and Development [MFDP], 2003). In turn, social protection has become one of the key strategies for poverty reduction and for achieving broader national goals of social justice, inclusive growth, and human and social development (MFDP, 1991, 2003; Vision 2036 Presidential Task Team, 2016).

Botswana's social protection system has evolved over time in response to emerging socioeconomic conditions and challenges. At independence, public policy emphasized supplementary feeding for primary school children and permanently destitute persons, as well as food-for-work programs (Botswana Institute for Development Policy Analysis [BIDPA], 2003, 2013; Fako \& Molamu, 1995; World Bank, 2015). Programs introduced during the 1970s and 1980s targeted marginalized people living in remote areas and individuals living in destitution (BIDPA, 2003; Ministry of Local Government, 2002). The 1990s saw the emergence of programs targeting poor and vulnerable groups (the elderly, orphans, and AIDS patients), whereas new programs in the 2000s emphasized economic empowerment, enterprise development, and employment creation.

Three broad social transfer mechanisms have traditionally been employed worldwide to target poor and vulnerable groups: (1) means-tested targeting, (2) categorical targeting, and (3) self-targeting (Lavallee, Olivier, Pasquier-Doumer, \& Robilliard, 2010; Legovini, 1999; Sabates-Wheeler, Hurrell, \& Devereux, 2015). Means-tested targeting involves the use of income or asset ownership thresholds in setting program eligibility criteria. Categorical targeting uses geographic or demographic distribution of poverty (age, geographic location, or vulnerability) as the criterion for selecting beneficiaries. Self-targeting involves voluntary enrollment of beneficiaries. Usually, program benefits are set so low (in either monetary value or quality) that only those individuals with few opportunities and greater need for the benefits are attracted to voluntarily enroll.

Two issues have featured prominently in the development literature concerning the delivery of transfers to beneficiaries: (1) effectiveness of programs in targeting the poor (Coady, Grosh, \& Hoddinott, 2004; Devereux et al., 2017; Sumarto, Suryahadi, \& Widyanti, 2002) and (2) whether means-tested programs are more effective in targeting the poor than programs employing other targeting mechanisms, particularly universal programs (Hanna \& Olken, 2018). This article will tackle these issues using household data for fifteen social transfer programs in Botswana (listed in table 1). It will add to related studies on the subject such as those by Seleka and colleagues (2007) and Tesliuc and colleagues (2013).

The next section of this article will provide a brief overview of the fifteen programs considered in the study (table 1), and the following section will describe the methodology for evaluating the targeting performance of the programs. After a brief discussion of the data, results and conclusions will be presented. 
Table 1 Social transfer programs and type of targeting

\begin{tabular}{ll}
\hline Acronym & Program name \\
\hline Means-tested targeting \\
DPP & Destitute Persons Program \\
NSP & Needy Student Package \\
CHBC & Community Home Based Care \\
LIMID & Livestock Management and Infrastructure Development \\
PEP & Poverty Eradication Program \\
Categorical targeting & \\
SFP & School Feeding Program \\
VGFP & Vulnerable Group Feeding Program \\
OCP & Orphan Care Program \\
OAP & Old Age Pension \\
WVP & World War II Veterans Program \\
RADP & Remote Area Development Program \\
YDF & Youth Development Fund \\
SA & Student Allowances \\
SCH & Scholarships \\
Self-targeted & \\
Ipelegeng & Ipelegeng Public Works Program \\
\hline
\end{tabular}

\section{Program Description}

\section{Means-tested Programs}

Five programs employ means testing: the Destitute Persons Program, Needy Student Package, Community Home-based Care (CHBC) Program, Livestock Management and Infrastructure Development (LIMID) Program, and Poverty Eradication Program. The major means-tested program, the Destitute Persons Program, provides welfare support to indigent persons and their dependents younger than eighteen. To be eligible for assistance under this program, an individual must earn monthly cash income not exceeding 150 pula (with dependents) or 120 pula (without dependents) and should own no more than four cattle (Ministry of Local Government, 2002). Each registered beneficiary receives a predetermined monthly food basket and cash amounting to 250 pula. Destitute persons' dependent children under the age of eighteen receive monthly food baskets equivalent to those prescribed for the Orphan Care Program (to be discussed later in this article). As part of the Destitute Persons Program, the Needy Student Package provides support to destitute persons' dependent children who attend school and other needy students from dysfunctional families.

Although it initially targeted terminally ill AIDS patients, the CHBC Program now also caters to patients suffering from diabetes, hypertension, and heart disease (Ministry of Health, 1996; Ministry of Local Government, 2005). 
Eligibility for the program is based on criteria for the Destitute Persons Program and also requires referral by a government medical doctor. Beneficiaries receive a CHBC monthly food basket or special food baskets prescribed by a government dietician. The LIMID Program, which aims to promote food security and eliminate destitution, is also means tested using criteria of the Destitute Persons Program. It provides grants not exceeding 12,000 pula for investment in sheep/goats, guinea fowls, or Tswana chicken production (Ministry of Agriculture, 2018). The Poverty Eradication Program, which aims to promote productive investment and eradicate absolute poverty, provides grants of up to 15,000 pula for investment in any of the forty-five prescribed enterprises. To be eligible, an individual must earn a monthly income not exceeding 366 pula.

\section{Categorical Programs}

Eight programs apply categorical targeting: the School Feeding Program, Vulnerable Group Feeding Program, Orphan Care Program, Old Age Pension Program, World War II Veterans Program, Remote Area Development Program, Youth Development Fund, and scholarships and sponsorships. The School Feeding Program provides meals to all children attending public primary and secondary schools. Primary school meals are intended to provide a third of each child's daily caloric requirement. In secondary schools, one meal is provided per weekday to non-boarders and three meals per day to boarders.

The Vulnerable Group Feeding Program, which targets children younger than five, medically selected pregnant and lactating mothers, and tuberculosis patients, provides prescribed monthly food baskets to beneficiaries at health facilities (Regional Hunger and Vulnerability Programme, 2011). The Orphan Care Program provides monthly food baskets, clothing and school uniforms, and psychosocial support to registered orphans under the age of eighteen (Seleka et al., 2007). The Old Age Pension Program provides pensions of 530 pula/month to all citizens aged sixty-five and older, whereas the World War II Veterans Program provides a cash allowance of 550 pula/month to World War II veterans (Regional Hunger and Vulnerability Programme, 2011), their surviving spouses, or their children under the age of twenty-one.

The Remote Area Development Program targets marginalized remote area communities to promote accelerated economic development, poverty reduction, and sustainable livelihoods (BIDPA, 2003). It targets communities with a population not exceeding 250 people or 50 households that are located fifteen kilometers or more from an officially recognized settlement (Republic of Botswana, 2010). Although its emphasis is on community projects, the Remote Area Development Program also helps eligible individuals access other social transfer programs.

The Youth Development Fund, which targets out-of-school, unemployed, or underemployed youth aged eighteen to thirty-five, provides start-up capital of up to 100,000 pula to individuals or 450,000 pula to youth groups to finance 
productive enterprises (Ministry of Youth Empowerment, Sport and Culture, 2017). Half of the funding is a grant and the rest is an interest-free loan. Sponsorships and scholarships are provided in the form of grants and loans for studies at tertiary institutions in Botswana and outside Botswana, respectively (World Bank, 2015).

\section{Self-targeted Programs}

Only one program, Ipelegeng (public works program), employs self-selected targeting. It provides temporary employment to vulnerable citizens aged eighteen or older on a rotational basis (Republic of Botswana, 2012). Each beneficiary works for a continuous period not exceeding six months and receives a wage of 567 pula/ month (651 pula/month for a supervisor) and a meal allowance of 8 pula/day.

\section{Methodology}

Measuring Program Coverage and Targeting Effectiveness

The authors have adopted the methodology employed by Sumarto and colleagues (2002) to assess the targeting effectiveness of the fifteen social transfer programs. The approach is illustrated in table 2. For each social transfer program, households are first divided into participants $(E)$ and nonparticipants $(F)$. Then participants and nonparticipants are further subdivided into the target $(G)$ and the nontarget $(H)$ groups. This leads to four subgroups: $A, B, C$, and $D$. Program participants $(E)$ include the target $(A)$ and the nontarget $(B)$ groups $(E=A+B)$. Similarly, program nonparticipants $(F)$ include the target $(C)$ and the nontarget (D) groups $(F=C+D)$. In the second column, the target group $(G)$ includes participants $(A)$ and nonparticipants $(C)(G=A+C)$. The nontarget group $(H)$ also includes participants $(B)$ and nonparticipants $(D)(H=B+D$. Finally, $I(=A+B+$ $C+D$ ) represents the total number of households.

Because the program's target group is $G(=A+C)$ and the program instead reaches households in group $E(=A+B)$, households in groups $A, D, B$, and $C$ represent successful targeting, successful exclusion, inclusion error or leakage, and

Table 2 Targeting effectiveness of social protection programs

\begin{tabular}{|c|c|c|c|}
\hline \multirow[t]{2}{*}{ Participation } & \multicolumn{2}{|c|}{ Population (I) } & \multirow[t]{2}{*}{ Total } \\
\hline & Target & Nontarget & \\
\hline Participants $(E)$ & A: Successful targeting & $\begin{array}{l}B \text { : Inclusion error } \\
\text { (leakage) }\end{array}$ & $E=A+B$ \\
\hline Nonparticipants $(F)$ & $\begin{array}{l}\text { C: Exclusion error } \\
\text { (under-coverage) }\end{array}$ & D: Successful exclusion & $F=C+D$ \\
\hline Total & $G=A+C$ & $H=B+D$ & $I=A+B+C+D$ \\
\hline
\end{tabular}

Sources: Coady et al. (2004); Dutrey (2007); Sumarto et al. (2002). 
exclusion error or under-coverage, respectively. Corresponding program performance indicators are:

$$
\begin{gathered}
\text { TER }=\frac{A}{E} \\
\mathrm{LR}=\frac{B}{E}=1-\text { TER } \\
\mathrm{CR}=\frac{A}{G} \\
\mathrm{UR}=\frac{C}{G}=1-C R
\end{gathered}
$$

where TER, LR, CR, and UR represent the targeting effectiveness ratio, leakage ratio, coverage ratio, and under-coverage ratio, respectively

A targeting effectiveness ratio of one or a leakage ratio of zero would suggest that all program participants belong to the target population or that no one in the nontarget population participates in the program. Conversely, a targeting effectiveness ratio of zero or a leakage ratio of one would imply that all program participants belong to the nontarget population or that no one in the target population participates in the program. A coverage ratio of one or an under-coverage ratio of zero would suggest that the entire target population is covered by the program. Conversely, a coverage ratio of zero or an under-coverage ratio of one would suggest that no one in the target population is covered by or participates in the program. We use the concept of relative poverty to identify poor and nonpoor program participants and nonparticipants (Sumarto et al., 2002). Households belonging to the lowest consumption quintile are classified as poor and those belonging to the remaining four upper consumption quintiles as nonpoor.

\section{Benefit Incidence}

First we normalized household consumption expenditure (henceforth referred to as consumption) and transfers. The best approach would be to adjust household consumption to an adult equivalent before undertaking distributional analysis. However, because this concept has not been adopted in Botswana, we proxied adult equivalent weights by normalizing the food poverty datum line (FPDL) for each individual in a household by the FPDL for an adult male residing in the city of Francistown.

The weight assigned to household member $j$ of age group $g$ and gender $n$ $(n=m, f)$ residing in geographical location $k$ was expressed as:

$$
w_{g n k}^{j}=F P D L_{g n k}^{j} / F P D L_{A m \mathcal{F}}^{j}
$$


where the numerator represents the FPDL for the respective individual and the denominator is the FPDL for an adult $(A)$ male $(m)$ residing in Francistown $(\mathcal{F})$. Equivalized consumption for household $h\left(E Y^{h}\right)$ was then expressed as:

$$
E Y^{h}=N^{h}\left(\frac{Y^{h}}{\sum_{j} w^{j h}}\right)
$$

where $Y^{h}$ represents the total consumption for household $h, N^{h}$ denotes the household size, and the term in parentheses is equivalized per capita consumption. Similarly, equivalized social transfers made to household $h$ through program $i\left(E m_{i}^{h}\right)$ were expressed as:

$$
E m_{i}^{h}=N^{h}\left(\frac{m_{i}^{h}}{\sum_{j} w^{j h}}\right)
$$

where $m_{i}^{h}$ denotes actual transfers received, and the term in parentheses is equivalized per capita transfers.

Benefit incidence analysis was carried out using program concentration curves, the Lorenz curve of consumption, and concentration indices. The share of program transfers $\left(S m_{i}^{d}\right)$ and the share of household consumption $\left(S Y^{d}\right)$ for households found in each equivalized per capita consumption decile $d$ were, respectively, derived as:

$$
\begin{aligned}
& S m_{i}^{d}=\frac{\sum_{h} E m_{i}^{h d}}{\sum_{h} E m_{i}^{h}} \\
& S Y^{d}=\frac{\sum_{h} E Y^{h d}}{\sum_{h} E Y^{h}}
\end{aligned}
$$

where the numerator and denominator of equation (8) represent total program transfers to households in decile $d(d=1,2, \ldots, 10)$ and total program transfers for all households, respectively. Similarly, the numerator and denominator of equation (9) represent total consumption for households in decile $d$ and total consumption for all households, respectively. At each reference decile $\tilde{d}$, the cumulative share of transfers $\operatorname{CSm}_{i}^{\tilde{d}}$ and cumulative share of consumption $C S Y^{\tilde{d}}$ were, respectively, derived as:

$$
\begin{aligned}
& \operatorname{CSm}_{i}^{\tilde{d}}=\sum_{d=1}^{\tilde{d}} S m_{i}^{d} \\
& \operatorname{CSY}^{\tilde{d}}=\sum_{d=1}^{\tilde{d}} S Y^{d}
\end{aligned}
$$

A plot of cumulative population shares by decile arranged by equivalized per capita consumption on the $x$-axis and cumulative shares of transfers on the $y$-axis 
yields the concentration curve. Similarly, a plot of cumulative population share against cumulative household share is the Lorenz curve of consumption.

The two curves were used with a $45^{\circ}$ line, or line of equality, to determine if transfers are pro-poor or not and progressive or regressive. If the concentration curve lies on the $45^{\circ}$ line, the transfer program equally benefits all households across the consumption distribution. A concentration curve lying above the $45^{\circ}$ line suggests that the program is pro-poor (Tesliuc et al., 2013). If the concentration curve lies above the Lorenz curve, the program is progressive because it performs better than the distribution of consumption; if the concentration curve lies below the Lorenz curve, the program is regressive because it performs worse than the distribution of consumption. If the concentration curve lies between the Lorenz curve and the $45^{\circ}$ line, the program is progressive but not pro-poor. Finally, if the concentration curve lies below the Lorenz curve, the program is regressive and not pro-poor (worst-case scenario).

The concentration index for program $i$ was expressed as:

$$
C_{i}=\sum_{t=1}^{T-1}\left(p_{i t} L_{i t+1}-p_{i t+1} L_{i t}\right)
$$

where $p_{t}(t=1, \ldots, 10)$ represents cumulative shares of the population arranged by consumption and $L_{i t}\left(=C S m_{i}^{\tilde{d}}\right)$ represents the corresponding cumulative shares of transfers (O'Donnell, van Dooslaer, Wagstaff, \& Lindelow, 2008). The range of $C_{i}$ is $-1 \leq C_{i} \leq 1$. If there is perfect equality in the distribution of social transfers, $C_{i}=0$. If the concentration curve falls above the line of equality, $C_{i}<0$ and the transfer program is pro-poor; if the concentration curve falls below the line of equality, $C_{i}>0$ and the program is not pro-poor. The Gini index of consumption was also computed using equation (12), but now with $L$ representing cumulative shares of consumption.

\section{Data}

The study used the 2015/16 Botswana Multi-topic Household Survey data set collected by Statistics Botswana. This data set contains information for 24,720 individuals from 7,060 households. When expansion factors are applied, the survey translates to an estimated 589,909 households and a national population of 2,073,675 individuals (Statistics Botswana, 2018).

The study relied heavily on module 8 , which captured information on social protection and other government assistance programs (Orphan Care and Destitute Persons Programs; CHBC, Vulnerable Group, and School Feeding Programs; Needy Student Package, Remote Area Development Programme; LIMID Programme; and Poverty Eradication Program) and aid packages (including World War II Veterans Program, Old Age Pension Program, student allowance, scholarships, and Youth Development Fund). We also utilized module 4, which captured information on Ipelegeng, for example. Information from these modules was merged into the main household data to facilitate analysis. Households with 
missing program transfer values were categorized as non-recipients. The data on the FPDLs used in the 2015/16 Botswana Multi-topic Household Survey were obtained from Statistics Botswana in spreadsheet format. These data contained FPDL estimates for seven geographical areas and eleven individual groups based on gender and age, which translates to seventy-seven FPDL estimates.

\section{Results and Discussion}

Program Coverage and Targeting

Table 3 reports performance ratios for the programs. Coverage ratio estimates are also depicted in figure 1. As shown, except for the School Feeding Program, which covered 68.1 percent of poor households, all social transfer programs had low coverage (or high under-coverage) of the poor. For example, the second and third best performers, the Old Age Pension Program and Ipelegeng, covered 25.1 and 13.3 percent of poor households, respectively. The remaining programs recorded coverage ratios of less than 3 percent, with the major means-tested programs, the Destitute Persons Program and Needy Student Package, covering 5.3 and 5.4 percent of poor households, respectively.

There is a positive association between program enrollment and coverage. For example, the School Feeding Program, Old Age Pension Program, and Ipelegeng have the highest enrollment and coverage ratio estimates. The Remote Area

Table 3 Program coverage and targeting indicators

\begin{tabular}{lcccc}
\hline Program & $\begin{array}{c}\text { Targeting effectiveness } \\
\text { ratio (\%) }\end{array}$ & $\begin{array}{c}\text { Leakage } \\
\text { ratio (\%) }\end{array}$ & $\begin{array}{r}\text { Coverage } \\
\text { ratio (\%) }\end{array}$ & $\begin{array}{c}\text { Under-coverage } \\
\text { ratio (\%) }\end{array}$ \\
\hline Means-tested targeting & & & & \\
DPP & 30.68 & 69.32 & 5.32 & 94.68 \\
NSP & 41.24 & 58.76 & 5.38 & 94.62 \\
CHBC & 15.65 & 84.35 & 0.15 & 99.85 \\
LIMID & 27.85 & 72.15 & 1.63 & 98.37 \\
PEP & 40.24 & 59.76 & 2.72 & 97.28 \\
Categorical targeting & & & & \\
SFP & 30.91 & 69.09 & 68.14 & 31.86 \\
VGFP & 31.44 & 68.56 & 0.25 & 99.75 \\
OCP & 17.95 & 82.05 & 2.31 & 97.69 \\
OAP & 33.46 & 66.54 & 25.13 & 74.87 \\
WVP & 37.88 & 62.12 & 0.49 & 99.51 \\
RADP & 8.04 & 91.96 & 0.08 & 99.92 \\
YDF & 21.70 & 78.30 & 0.24 & 99.76 \\
SA & 6.84 & 93.16 & 1.41 & 98.59 \\
Scholarships & 8.08 & 91.92 & 0.88 & 99.12 \\
Self-targeted & & & & \\
Ipelegeng & 41.44 & 58.56 & 13.31 & 86.69 \\
\hline
\end{tabular}

Source: Computed by the author from the 2015/16 Botswana Multi-topic Household Survey (Statistics Botswana, 2018). 


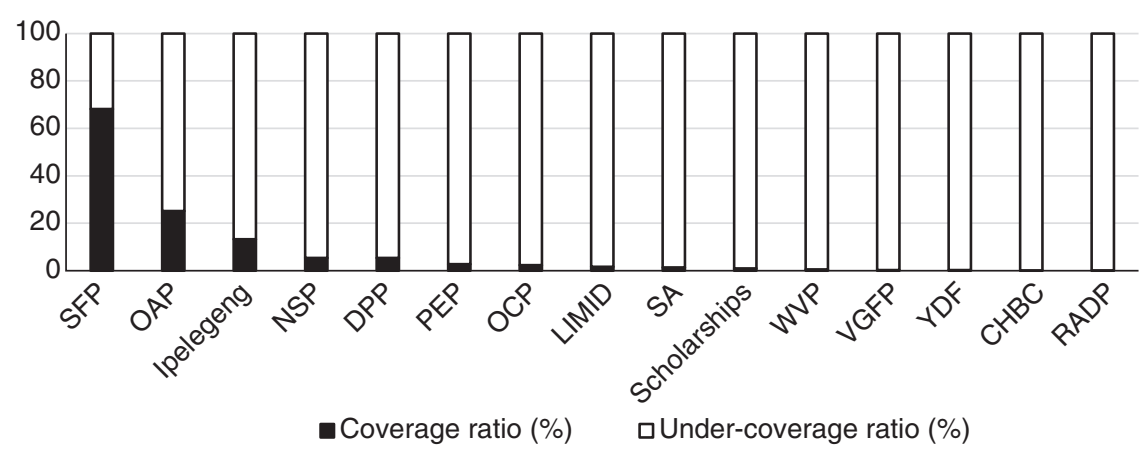

Figure 1 Coverage and under-coverage of the poor, 2015/16

Source: Computed by the author from the 2015/16 Botswana Multi-topic Household Survey (Statistics Botswana, 2018)

Development Program, CHBC Program, Vulnerable Group Feeding Program, Youth Development Fund, and World War II Veterans Program have the lowest enrollment and coverage ratio estimates (see table 4).

Means-tested programs do not necessarily outperform programs employing categorical or self-selected targeting. For example, the Needy Student Package, Destitute Persons Program, and Poverty Eradication Program rank fourth, fifth, and sixth, respectively, and are surpassed by two categorical programs (the School Feeding Program and Old Age Pension Program) and a self-targeted program (Ipelegeng).

Evidently, all programs have low targeting effectiveness ratios and high leakage ratios (see table 3 and figure 2). For example, only 41.4, 41.2, and 40.2 percent of the beneficiaries of Ipelegeng, the Needy Student Package, and the Poverty Eradication Program were poor; conversely, 58.6, 58.8, and 59.8 percent of the beneficiaries were nonpoor. Further, only 30.7 percent of participants in the Destitute Persons Program were poor. The worst performer, the Remote Area Development Program, recorded a targeting effectiveness ratio of only 8.0 percent and a leakage ratio of 92.0 percent.

Means-tested programs to not necessarily perform better in targeting the poor. The best performer (Ipelegeng) employs self-targeting. Although the second and third best performers (the Needy Student Package and Poverty Eradication Program) employ means testing, it is a concern that the major means-tested program (the Destitute Persons Program) ranks seventh and is outperformed by a self-targeted program (Ipelegeng) and several programs employing categorical targeting (the World War II Veterans Program, Old Age Pension Program, Vulnerable Group Feeding Program, and School Feeding Program).

Distribution of Program Beneficiaries across Consumption Quintiles

Table 4 shows the distribution of program beneficiaries across consumption quintiles. As shown, five programs exhibited consistent inverse relationships between 


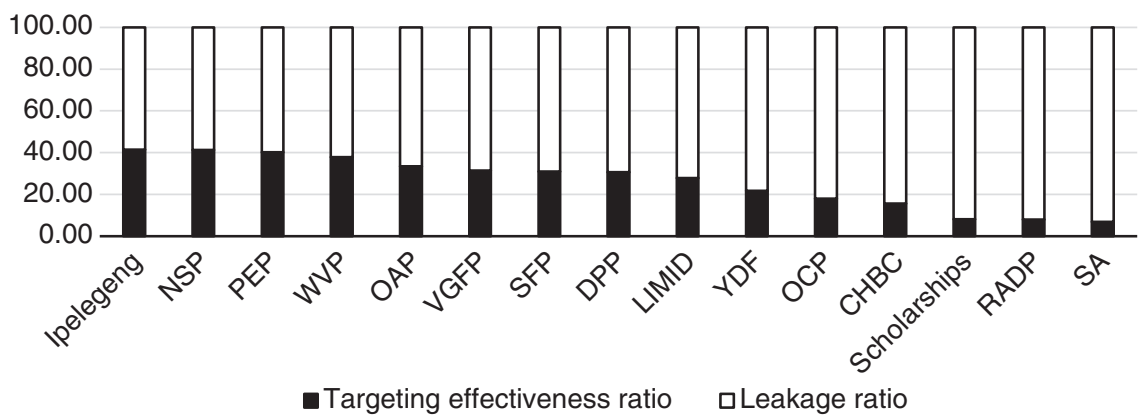

Figure 2 Program targeting effectiveness and leakage, 2015/16

Source: Computed by the author from the 2015/16 Botswana Multi-topic Household Survey. (Statistics Botswana, 2018)

Table 4 Distribution of program beneficiary households by consumption quintile, 2015/16

\begin{tabular}{|c|c|c|c|c|c|c|}
\hline \multirow[t]{2}{*}{ Program $^{\dagger}$} & \multicolumn{5}{|c|}{$\begin{array}{c}\text { Percentage of beneficiary households } \\
\text { Quintile* }\end{array}$} & \multirow{2}{*}{$\begin{array}{c}\text { No. of } \\
\text { beneficiary } \\
\text { households }\end{array}$} \\
\hline & Q1 & Q2 & Q3 & Q4 & Q5 & \\
\hline \multicolumn{7}{|c|}{ Means-tested targeting } \\
\hline DPP & 30.7 & 33.4 & 21.5 & 11.6 & 2.8 & 19,552 \\
\hline NSP & 41.2 & 33.8 & 18.6 & 5.4 & 0.9 & 14,709 \\
\hline $\mathrm{CHBC}$ & 15.6 & 25.2 & 41.5 & 8.1 & 9.6 & 1,080 \\
\hline LIMID & 27.8 & 31.4 & 16.8 & 14.5 & 9.5 & 6,582 \\
\hline PEP & 40.2 & 27.9 & 18.4 & 9.1 & 4.3 & 7,605 \\
\hline \multicolumn{7}{|c|}{ Categorical targeting } \\
\hline SFP & 30.9 & 24.6 & 17.8 & 14.6 & 12.1 & 248,466 \\
\hline VGFP $^{+}$ & 31.4 & 27.4 & 15.9 & 17.5 & 7.8 & 901 \\
\hline OCP & 17.9 & 34.0 & 31.9 & 8.0 & 8.2 & 14,474 \\
\hline OAP & 33.5 & 25.0 & 22.3 & 13.3 & 5.9 & 84,659 \\
\hline WVP & 37.9 & 20.6 & 13.1 & 4.0 & 24.4 & 1,460 \\
\hline RADP & 8.0 & 31.9 & 23.9 & 12.5 & 23.6 & 1,156 \\
\hline YDF & 21.7 & 15.9 & 23.8 & 26.3 & 12.4 & 1,267 \\
\hline SA & 6.8 & 12.8 & 23.6 & 28.6 & 28.2 & 23,291 \\
\hline Scholarships & 8.1 & 12.8 & 19.0 & 27.1 & 33.1 & 12,330 \\
\hline \multicolumn{7}{|l|}{ Self-targeted } \\
\hline Ipelegeng & 41.4 & 32.3 & 16.0 & 8.1 & 2.1 & 36,199 \\
\hline
\end{tabular}

Source: Computed by the auth
(Statistics Botswana, 2018).

*Equivalized per capita consumption $E_{y}$ quintiles are Q1: $\mathrm{E}_{y} \leq 479.20 ; \mathrm{Q} 2: 479.20<\mathrm{E}_{\mathrm{y}} \leq 824.40$; Q3: 824.40< $\mathrm{E}_{\mathrm{y}} \leq 1380.76$; Q4: 1380.76< $\mathrm{E}_{\mathrm{y}} \leq 2602.34 ; \mathrm{E}_{\mathrm{y}}>2602.34$.

'Enrollment for the Vulnerable Group Feeding Program should be interpreted with care because it appears to be underestimated and may have excluded children under age five. 
per capita consumption and the number of beneficiaries. These include two means-tested programs (Needy Student Package and Poverty Eradication Program), two categorical/universal programs (School Feeding Program and Old Age Pension Program) and one self-targeted program (Ipelegeng). The Destitute Persons Program and LIMID Program, both means-tested, exhibited similar patterns, except that they had slightly more beneficiaries recorded in quintile 2 than in quintile 1. The Vulnerable Group Feeding Program and the Orphan Care Program also exhibited an inverse relationship, except that the former had more participants in quintile 4 than in quintile 3 , and the latter recorded higher proportions of participants in quintiles 2 and 3 than in quintile 1. The World War II Veterans Program is a special case because it shows a consistent reduction in the shares of beneficiaries from quintile 1 to quintile 4 and a substantial jump in quintile 5; the highest share was recorded in quintile 1 , followed by quintile 5 . Thus, subject to further analysis, it appears that at least ten of the fifteen programs may be pro-poor.

Three of the remaining five programs (the CHBC Program, Remote Area Development Program, and Youth Development Fund) do not show discernible patterns in the distribution of beneficiaries. The remaining two programs, student allowance and scholarships, which employ categorical targeting, generally exhibit positive association between per capita consumption and the number of program beneficiaries; hence, they are not pro-poor.

\section{Benefit Incidence}

Figures 3a through 3e are plots of the concentration curves for the fifteen programs, as well as the Lorenz curve of consumption. Figures 3 a through $3 \mathrm{c}$ reveal that eight programs, including four means-tested programs (Destitute Persons Program, Needy Student Package, LIMID Program, and Poverty Eradication Program), three categorical programs (World War II Veterans Program, School Feeding Program, and Old Age Pension Program) and one self-targeted program (Ipelegeng), are pro-poor. Figure 3a shows that the Needy Student Package may be more pro-poor than the Destitute Persons Program except for the ambiguity at the bottom consumption decile.

Figure 3b reveals that the Old Age Pension, World War II Veterans Program, School Feeding Program, and Ipelegeng outperformed the Destitute Persons Program up to the bottom 20,40,60, and 80 percent of the population, respectively; beyond these deciles either the reverse prevailed or indiscernible differences were observed. Figure 3c shows that the Destitute Persons Program generally outperformed the LIMID Program except at the bottom 10 percent of the population distribution. Lastly, the Poverty Eradication Program outperformed the Destitute Persons Program at the bottom 40 percent of the population distribution, after which no discernible differences could be established. Broadly, it cannot be concluded whether the Destitute Persons Program is more pro-poor than the other seven programs depicted in figures 3a through 3c. 


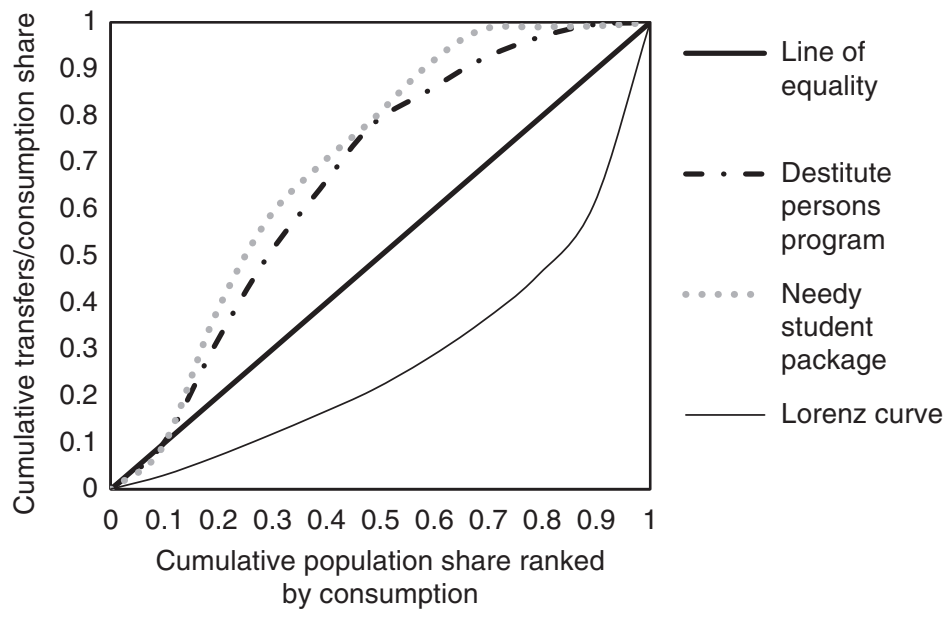

Figure 3a Concentration curves for the Destitute Persons Program and the Needy Student Package, 2015/16

Source: Computed by the author from the 2015/16 Botswana Multi-topic Household Survey (Statistics Botswana, 2018).
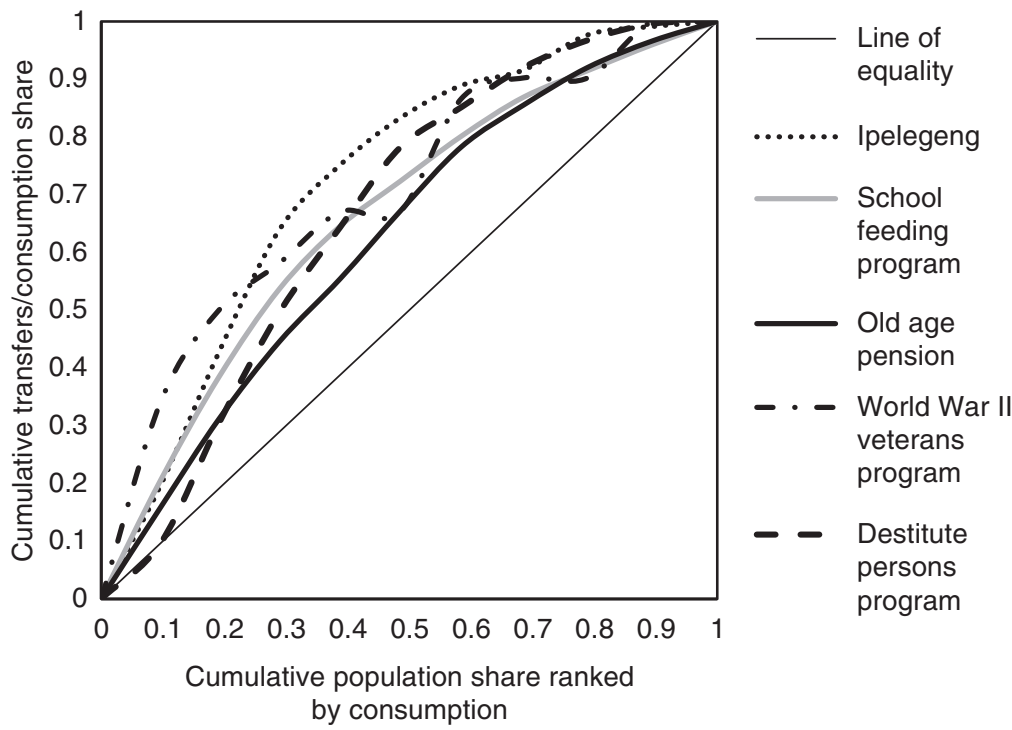

Figure 3b Concentration curves for Destitute Persons Program, Ipelegeng, Old Age Pension, School Feeding Program, and World War II Veterans Program, 2015/16

Source: Computed by the author from the 2015/16 Botswana Multi-topic Household Survey (Statistics Botswana, 2018). 

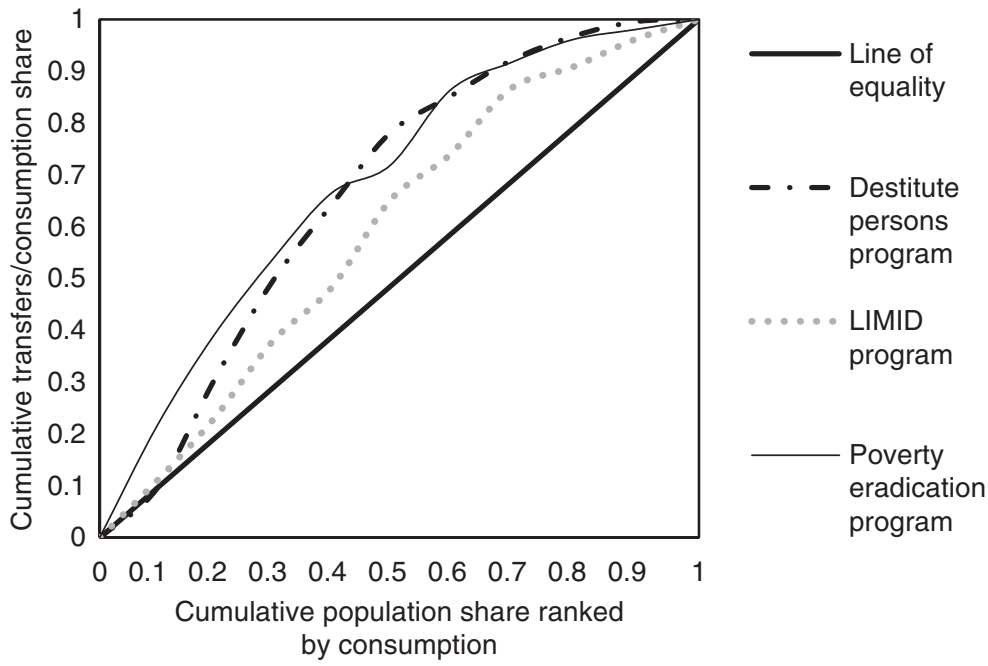

Figure 3c Concentration curves for the Destitute Persons Program, LIMID Program, and Poverty Eradication Program, 2015/16

Source: Computed by the author from the 2015/16 Botswana Multi-topic Household Survey (Statistics Botswana, 2018).

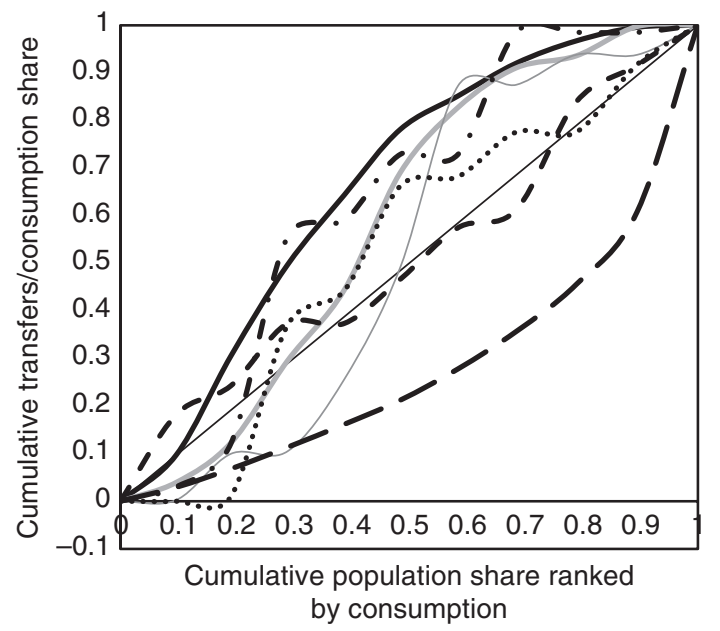
L Line of equality
Destitute persons program
Orphan care program
Community home-based care

- - Lorenz curve

Remote area development program

- - - Youth development fund

- - Vulnerable group feeding program

Figure 3d Concentration curves for the Destitute Persons Program, Orphan Care Program, CHBC Program, Remote Area Development Program, Youth

Development Fund, and Vulnerable Group Feeding Program, 2015/16

Source: Computed by the author from the 2015/16 Botswana Multi-topic Household Survey (Statistics Botswana, 2018). 


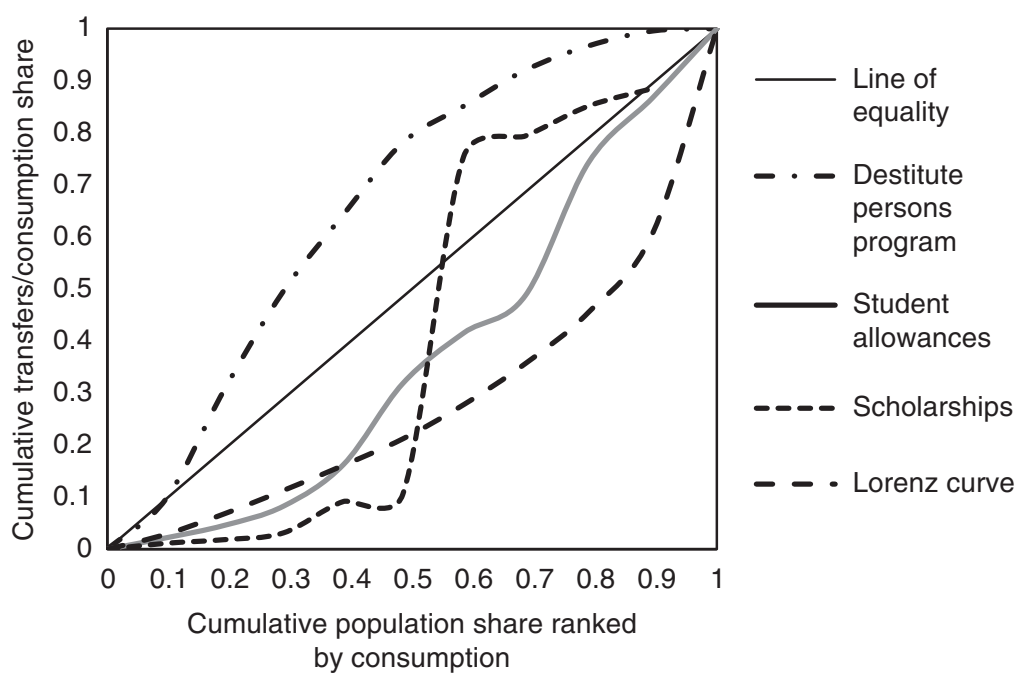

Figure 3e Concentration curves for the Destitute Persons Program, Student Allowances and Scholarships, 2015/16

Source: Computed by the author from the 2015/16 Botswana Multi-topic Household Survey (Statistics Botswana, 2018).

The remaining seven programs reveal mixed results in terms of being pro-poor and progressive or regressive. The Youth Development Fund performed well up to the bottom 30 percent of the population distribution (figure $3 \mathrm{~d}$ ). On the contrary, the Vulnerable Group Feeding Program, Orphan Care Program, CHBC Program, and Remote Area Development Program performed more poorly at lower than at higher consumption levels, with the concentration curves for the Remote Area Development and CHBC Programs falling below the Lorenz curve at lower consumption levels. Finally, scholarships and student allowance were the worst performers (figure 3e) and were not pro-poor. This is particularly obvious for scholarships because the concentration curve for this program consistently fell below the line of equality.

Figure 4 shows that thirteen programs registered negative concentration indices and therefore appear to be pro-poor and that two programs (with positive indices) are not pro-poor. When combining the results from the distribution of beneficiaries across consumption quintiles, concentration curves, and concentration indices, we draw the following conclusions. First, nine programs (Ipelegeng, World War II Veterans Program, Needy Student Package, Poverty Eradication Program, Destitute Persons Program, Student Feeding Program, Vulnerable Group Feeding Program, Old Age Pension Program, and LIMID Program) are pro-poor and progressive. Second, although they have negative concentration indices, four programs (Orphan Care Program, Remote Area Development Program, CHBC Program, and Youth Development Fund) are not necessarily pro-poor because 


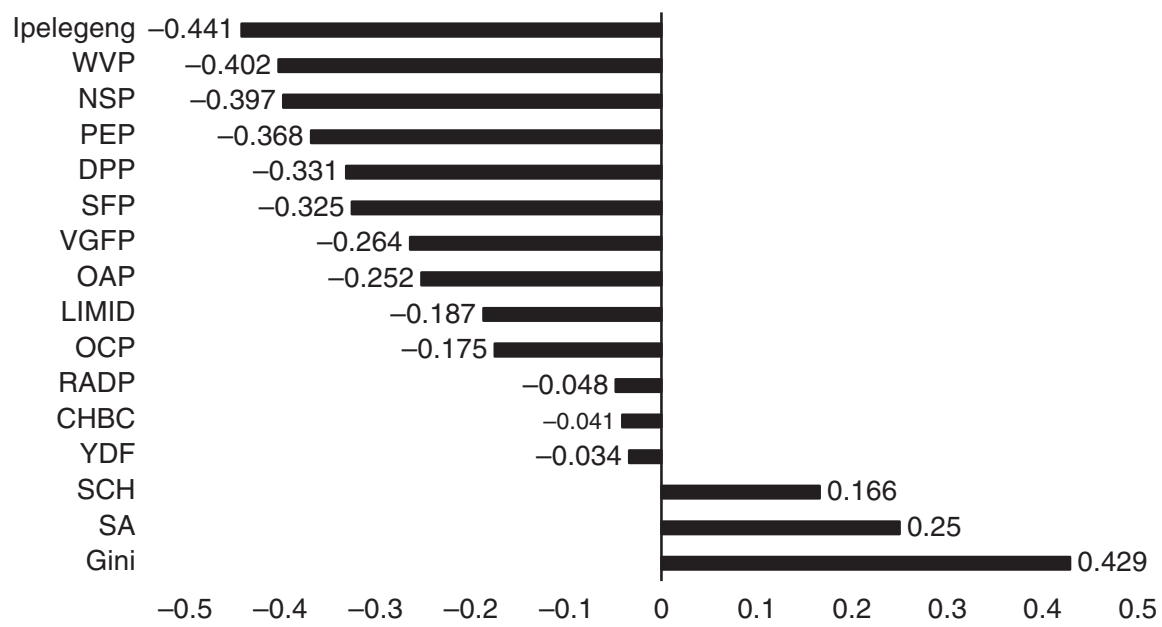

Figure 4 Concentration indices for social transfer programs in Botswana, 2015/2016 Source: Computed by the author from the 2015/16 Botswana Multi-topic Household Survey (Statistics Botswana, 2018).

Note: The Gini coefficient is lower than the Statistics Botswana estimate of 0.522 because the current estimate used the household (rather than an individual) as a unit of analysis.

they exhibit concentration curves that fall both below and above the line of equality, but they are progressive. Third, with positive concentration indices, two programs (student allowance and scholarships) are not pro-poor, but are progressive in that their concentration indices are smaller than the Gini coefficient of consumption. Fourth, means-tested programs do not necessarily outperform programs employing other targeting mechanisms. For example, the Needy Student Package, Destitute Persons Program, and Poverty Eradication Program, which are all means tested, rank third, fourth, and fifth, respectively, based on the concentration indices, and are surpassed by Ipelegeng and the World War II Veterans Program. The LIMID Program, also means tested, ranked ninth based on the concentration index and is surpassed by many categorical programs and a selftargeted program.

\section{Conclusions and Policy Implications}

The foregoing analysis has revealed that social transfer programs in Botswana are associated with low coverage (high under-coverage) of poor households; the exception is the School Feeding Program, which covers about two-thirds of poor households. Because they leave many poor households without coverage, these programs have limited effectiveness in reducing poverty. There is no association between coverage ratios and the targeting mechanism employed because the low coverage rates are common to all the three targeting mechanisms. For all programs, the targeting effectiveness ratios are exceeded by leakage ratios, implying underperformance in 
targeting the poor, particularly for means-tested programs, which are expected to perform better. Contrary to expectation, means-tested programs do not necessarily target the poor better than categorical and self-targeted programs.

Benefit incidence analysis reveals that most programs are pro-poor. These include seven social assistance programs delivering cash and in-kind food transfers to beneficiaries (Ipelegeng, World War II Veterans Program, Needy Student Package, Destitute Persons Program, School Feeding Program, Vulnerable Group Feeding Program, and Old Age Pension Program) and two asset transfer (investment) programs (Poverty Eradication Program and LIMID Program). However, inconsistent results were obtained for four programs (Orphan Care Program, Remote Area Development Program, CHBC Program, and Youth Development Fund) that, although progressive, are not definitively pro-poor. Programs meant to promote investment in human capital development (student allowance and scholarships) were found to be progressive but not pro-poor. Because these programs are provided universally to qualifying students at tertiary institutions, the results imply that children from lower income households have lower rates of progression to tertiary education than those from higher income households. Because education enhances welfare in Botswana (Lekobane \& Seleka, 2017), this situation may contribute to intergenerational transmission of poverty from parents to their children.

Although it is commendable that most means-tested programs are pro-poor, it is disconcerting to learn that they do not necessarily outperform programs employing categorical and self-targeted mechanisms. This may suggest that identification and selection methods are not sufficiently robust to select the poorest of the poor or that eligibility criteria are not strictly enforced during selection. Improved identification and selection methods and adherence to eligibility criteria, particularly for the major means-tested programs (the Destitute Persons Program and Needy Student Package), would improve both coverage and targeting effectiveness of these programs.

Another concern is that eligibility criteria for the Destitute Persons Program, which are also applied to several other means-tested programs, have remained unchanged since the inception of the program in 1980. Yet poverty datum lines have changed over time due to evolving social and economic conditions. About four decades since the eligibility criteria were adopted, this raises additional doubt as to whether they are still strictly enforced. Therefore, means testing criteria should be reviewed to accommodate the changed economic and social environments.

\section{References}

Botswana Institute for Development Policy Analysis. (2003). Report on the review of the Remote Area Development Programme (RADP). Gaborone, Botswana: Author. Retrieved from https://www.africaportal.org/publications/ report-on-the-review-of-the-remote-area-development-programme-radp 
Botswana Institute for Development Policy Analysis. (2013). Botswana National Primary Feeding Programme: A case study. Gaborone, Botswana: Author.

Coady, D., Grosh, M., \& Hoddinott, J. (2004). Targeting of transfers in developing countries: Review of lessons and experiences. Washington, DC: World Bank

Devereux, S., Masset, E., Sabates-Wheeler, R., Samson, M., Rivas, A. M., \& Lintelo, D. (2017). The targeting effectiveness of social transfers. Journal of Development Effectiveness, 9, 162-211.

Dutrey, A. P. (2007). Successful targeting? Reporting efficiency and costs in targeted poverty alleviation programs. Geneva, Switzerland: United Nations Institute for Social Development.

Fako, T. T., \& Molamu. L. (1995). The seven-year drought, household food security and vulnerable groups in Botswana. Pula: Botswana Journal of African Studies, $9(2), 48-70$.

Hanna, R., \& Olken, B. A. (2018). Universal basic incomes versus targeted transfers: Anti-poverty programs in developing countries. Journal of Economic Perspectives, 32(4), 201-226.

Lavallée, E., Olivier, A., Pasquier-Doumer, L., \& Robilliard, A. S. (2010). Poverty alleviation policy targeting: A review of experiences in developing countries (Working paper DT/2010/10). Paris, France: Développement, Institutions et Mondialisation.

Legovini, A. (1999). Targeting methods for social programs (Poverty \& inequality technical note 1). Washington, DC: Inter-American Development Bank. Retrieved from: https://pdfs.semanticscholar.org/e486/01d8333cb 5f114eaa9818b706d55600a7f84.pdf

Lekobane, K. R., Seleka, T. B. (2017). Determinants of household welfare and poverty in Botswana, 2003/04 and 2009/10. Journal of Poverty, 21, 42-60.

Maipose, G. S. (2008). Institutional dynamics of sustained rapid economic growth with limited impact on poverty reduction. Geneva, Switzerland: United Nations Research Institute for Social Development. Retrieved from http://www.unrisd. org/unrisd/website/document.nsf/(httpPublications)/4365C57157F 8EF 16C1257AEF00525641?OpenDocument

Ministry of Agriculture. (2018). Livestock Management and Infrastructure Development (LIMID) Programme smallstock package: Application form for resource-poor component. Retrieved from http://www.gov.bw/globalassets/ministry-ofagriculture/limid-4.pdf

Ministry of Finance and Development Planning. (1991). National development plan 7: 1991-1997. Gaborone, Botswana: Government Printer.

Ministry of Finance and Development Planning. (2003). National strategy for poverty reduction of 2003. Gaborone, Botswana: Government Printer.

Ministry of Health. (1996). Community home-based care for people with AIDS in Botswana: Operational guidelines. Gaborone, Botswana: Author.

Ministry of Local Government. (2002). Revised national policy on destitute persons. Gaborone, Botswana: Author.

Ministry of Local Government. (2005). Guidelines for provision of social safety net for community home based care patients. Gaborone, Botswana: Author. 
Ministry of Youth Empowerment, Sport and Culture. (2017). Youth Development Fund guidelines. Gaborone, Botswana: Author.

O’Donnell, O., van Dooslaer, E., Wagstaff, A., \& Lindelow, M. (2008). Analyzing health equity using household survey data: A guide to techniques their implementation. Washington DC: World Bank. Retrieved from http://siteresources.worldbank. org/INTPAH/Resources/Publications/459843-1195594469249/ HealthEquityFINAL.pdf

Regional Hunger and Vulnerability Programme. 2011. Social protection in Botswana-A model for Africa? Frontiers of Social Protection (Brief no. 9). Retrieved from http://interactions.eldis.org/sites/interactions.eldis.org/files/ database_sp/Botswana/Vulnerable\%20Group\%20Feeding\%20Programme/ VGF\%201.pdf

Republic of Botswana. (2010). A social development policy framework for Botswana, Phase 1: Situational analysis. Gaborone, Botswana: Government Printer. Retrieved from https://social-assistance.africa.undp.org/sites/default/ files/resources/Botswana_A\%20Social\%20Development\%20Policy\%20 Framework\%20for\%20Botswana_2010.pdf

Sabates-Wheeler, R., Hurrell, A., \& Devereux, S. (2015). Targeting social transfer programs: Comparing design and implementation errors across alternative mechanisms. Journal of International Development, 27, 1521-1545.

Seleka, T. B., Siphambe, H., Ntseane, D., Mbere, N., Kerapeletswe, C., \& Sharp, C. (2007). Social safety nets in Botswana: Administration, targeting and sustainability. Gaborone, Botswana: Lightbooks. Retrieved from http://www.bidpa.bw/ img_upload/pubdoc_47.pdf

Statistics Botswana. (2018). Botswana multi-topic household survey report 2015/16. Gaborone, Botswana: Author. Retrieved from http://www.statsbots.org. bw/sites/default/files/Botswana\%20Multi\%20Topic\%20Household\%20 Survey\%20REPORT\%202015\%2016.pdf

Sumarto, S., Suryahadi, A., \& Widyanti, W. (2002). Designs and implementation of Indonesian social safety net programs. Developing Economies, 40, 3-31.

Tesliuc, C., Marques, J. S., Lekobane, K. R., Mookodi, L., Bezhanyan, A., Braithwaite, J. . . . Schmalzbach, M.; (2013). Botswana social protection assessment. Gaborone, Botswana: World Bank.

Ulriksen, M. S. (2012). Questioning the pro-poor agenda: Examining links between social protection and poverty. Development Policy Review, 30, 261-281.

United Nations Development Programme. (2009). Assessment of development results: Evaluation of UNDP contribution-Botswana. New York, NY: United Nations.

Vision 2036 Presidential Task Team. (2016). Vision 2036: Achieving prosperity for all. Gaborone, Botswana.

World Bank. (2015). Botswana poverty assessment (Report no. 88473-BW). Gaborone: World Bank. Retrieved from http://documents.worldbank.org/ curated/en/351721468184754228/Botswana-poverty-assessment

World Bank. (2019). The World Bank in Botswana: Overview. Retrieved from https:// www.worldbank.org/en/country/botswana/overview 